\title{
Modern Designs of Forest Fires Machines for Soil Extinguishment of Fire
}

\author{
Bartenev Ivan Mihailovich \\ (a) Forest Mechanization and Machine Design dept. \\ (b) Voronezh State University of Forestry and Technologies \\ named after G.F. Morozov \\ Voronezh, Russia \\ kafedramehaniza@mail.ru
}

\author{
Gnusov Maxim Alexandrovich \\ Personnel Recruitment Center LLC \\ Voronezh, Russia \\ ko407@yandex.ru
}

\author{
Malyukov Sergey Vladimirovich \\ (a) Forest Mechanization and Machine Design dept. \\ (b) Voronezh State University of Forestry and Technologies \\ named after G.F. Morozov \\ Voronezh, Russia \\ malyukovsergey@yandex.ru
}

\section{Stupnikov Dmitriy Sergeevich}

(a) Forest Mechanization and Machine Design dept.

(b) Voronezh State University of Forestry and Technologies named after G.F. Morozov

Voronezh, Russia

neiti1992@mail.ru

Platonov Alexey Dmitrievich

(a) Wood Science dept

(b) Voronezh State University of Forestry and Technologies named after G.F. Morozov

Voronezh, Russia

aleksey66@yandex.ru

\begin{abstract}
Theoretical issues of the use of a fire-fighting soilthrower for extinguishing forest fires with the presentation of its practical use in conditions of high fire risk are considered. To assess the effectiveness of the use of new units in the article, a study of the information base for the use of existing technology in modern conditions has been conducted. Promising directions for improving the technology and working bodies of soil throwing machines are described; the advantages and disadvantages of their structures are identified, and ways for further improvement are outlined.

In order to eliminate the identified shortcomings, a promising design of a combined machine for extinguishing forest fires with soil, which contains a frame, a linkage mechanism, auger, a ripper, spherical disks, support wheels, skids, and a working body in the form of cutters (front and rear), gearbox, guiding jackets, hydraulic cylinders, transmission, safety devices is presented. A distinctive feature of the developed design of the fire-fighting soil-thrower is to increase the efficiency of the operation of the dirt throwing machine and fire-break maker by removing the upper fire-hazardous cover consisting of plant residues. This is achieved due to the fact that a device in the form of a double-sided auger installed in front of the discs is inserted into the design of the primer-stripper. The auger shifts the ground cover from the center to the left and right sides, forming an open mineralized strip.
\end{abstract}

Keywords - forest fires, soil, fire-fighting soil-thrower, fire suppression.

\section{INTRODUCTION}

Forests are important parts of the ecosystems and play a significant role to preserve and maintain the environment. The main hazard is forest fires because their consequences are terrible in nature. Therefore, there is a need to detect fire and to extinguish it before it spreads to destroy the resources [1]. The forest fire spreading is a complex process affected by multi-factors. Understanding the relationships between these multi-factors and the forest fire-spreading trend is vital to predicting the fire spreading promptly and accurately, creating the strategy in extinguishing the forest fire [2-11].

A forest fire is uncontrolled wildfire spreading in a wooded area. The causes of forest fires are commonly classified as natural or anthropogenic. Usually lightning is the most common natural cause of big forest fires on Earth. Today, the proportion of fires that are natural (caused by lightning) is $7 \%-8 \%$ of the total, i.e. most forest fires are caused by human activities. Therefore, there is an urgent need for the work of fire services and the regulation of the observation of fire safety requirements.

Sometimes fires are artificially induced. Such fires are generally referred to as controlled. The objective of controlled fires is: the destruction of fire-hazardous combustible materials, the disposal of wood wastes, the preparation of plots for the planting of seedlings, the control of pests and forest diseases etc., as well as the intentional triggering of forest fires 
for the purpose of further felling (e.g. in the Russian Far East areas bordering with China).

Recently the summer in Russia has been unusually hot and dry. The heat is causing large forest fires, which did not happen previously. Lives are lost, many houses and much infrastructure are destroyed, and hundreds of thousands of hectares of forest are burned. In view of these events, requirements for forest protection have increased. At present, there is a dramatic increase in resources for fire management and material resources for forest fire-fighting agencies. This results in the continuous search for new means of forest fire fighting, as well as the perfection of existing methods and technical means. It is a well-known fact that it is easier to detect and extinguish a fire at its early stages than to fight an already-raging force.

\section{EXPERIMENTAL PART}

Water is the most widespread way of fighting forest fires. It is used for extinguishing upper, ground and soil forest fires, whereby, depending on the kind of fire, the fire spread conditions, the availability of water and the type of mechanisms used, the application of this fire-fighting method can be used for localization, as well as complete extinguishing.

Water is taken from lakes, rivers, springs and other water bodies close to the fire or supplied in fire-fighting tank vehicles and in tanks of special forest fire-fighting units.

To extinguish forest fires, water pump units of fire-fighting tank vehicles, plunging pumps operating from tractor engines, fire power pumps (portable, trailed, small-sized) and forest fire extinguishers are used.

Fire extinguishing is also performed with the help of airplanes and helicopters. Extinguishing fires with the help of aviation is very expensive and not always efficient. If there is a large fire area perimeter and complicated fire edge, single discharges even of large quantities of water on limited areas do not produce significant effects. It is difficult to discharge water exactly along the fire edge. It is also difficult to define the particular location of the ground fire edge due to smoke shift and total smoke coverage. Additionally, another disadvantage of fire-fighting aviation is the need for very time-consuming refueling. Use of fire-fighting aviation considerably complicates the work of other fire brigades because of the injury risk when discharging large quantities of water. Use of fire-fighting aviation to a great extent is justified in case of intensive upper fire reaching important infrastructure. It is expedient to extinguish ground fire using cheaper and more effective methods.

One of the most well known and widely used methods for extinguishing ground forest fires is making a mineralized fire break some distance from the fire and throwing soil for suppressing the fire. Making mineralized firebreaks is a preventive and precautionary measure. Firebreaks are made on the borders of wooded lands adjacent to railroads, agricultural lands, highways, livestock farms, populated settlements and other objects.
It is not beneficial and sometimes impossible to fight forest fires with water and with fire-extinguishing compositions because of the origin area of the fire; use of soil for forest fire extinguishing has a great potential, as there is always large quantity of soil in close proximity to a fire.

At the moment there are numbers of designs of soilthrowers [12-18]. Their common design feature is the presence of rapidly rotating working bodies engaged in the milling of the top layer of soil and throwing it towards the fire. We represent several such units.

The universal soil-thrower is related to devices intended for laying mineral support and protective strips.

It contains (Fig. 1) ball-type coupling device 1, including a housing with a spherical recess, sliding block with a spherical surface and a movable element with a handle that controls the coupling process and is equipped with a clamp, frame 2 with suspension on swinging balancers 3 and wheels 4 , internal combustion engine 5 with manual or electric starter 6 , a lever for adjusting the height of working body 7 , belt drive 8 consisting of driving and driven pulleys located at some distance from each other and bending around the drive belt, actuating the working body with cutting-throwing blades 11 , fixed on the circumference of disk 9 on movable hinges 10 , protective housing 12 .

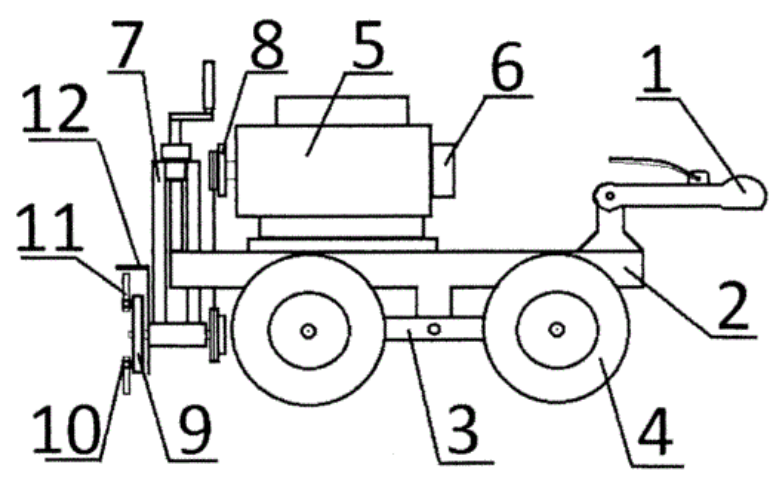

Fig. 1. General view of universal soil-thrower

The soil-thrower works as follows: it is brought in actuation by connecting ball-type coupling device 1, attached to frame 2 with suspension on swinging balancers 3 and wheels 4 with an all-terrain vehicle equipped with a coupling ball. Internal combustion engine 5 is started by manual or electric starter 6 . The torque from engine 5 is transmitted through belt drive 8 to the working body mounted on the height adjusting lever of working body 7 . When the working body rotates, cutting and throwing knives 11 mounted on disk 9 take the working position due to centrifugal force and can absorb shock loads from the roots and other obstacles when laying mineralized strip, as they are made freely swinging around the circumference of disk 9 of hinges 10 . This creates a mineralized strip and the ejection of the soil by removing the upper part of soil and soil with cutting knives, the depth of which is regulated by tilting the lever for adjusting the height of working body 7 . And when moving the soil-thrower that relies on the soil by hanging on balancers 3 with wheels 4 , 
smoothing of uneven ground occurs [19].

Thus, due to the fact that the soil-thrower has a ball-type traction coupling device, an autonomous engine, actuated by a belt transmission, has a working body with cutting-throwing knives mounted around the moving hinges and arranged independently, and the suspension is made on swinging balancers with wheels. Thus, it is possible to use it with various types of off-road vehicles that do not have a power take-off shaft and are equipped with a hitch ball, smoothing uneven soil springs when working due to suspension on swinging balancers, damping shock loads from roots and other obstacles when laying mineralized strip by a working body.

The frontal soil-thrower is designed for laying protective mineralized strips, as well as for extinguishing ground fires with soil, especially in waterless forests.

The frontal soil-thrower (Fig. 2) includes base machine 1, carrier frame 2 , and working body 3 . Working body 3 is installed on swing axis 4 , taken out of the center of mass of the working body, for deepening working body 3 . Swing axis 4 is stationary fixed at one end of guide housing 5; it is pivotally connected to supporting frame 2 with the other end. On frame 2, hydraulic cylinders 6, lifting and lowering supporting frame 2 , are mounted loading hydraulic cylinder 7 lifting and lowering working body 3 . On housing 5, power installation 8 and lever 9 are fixed. Lever 9 at one end is motionlessly mounted on housing 5 ; the other end is pivotally connected to hydraulic cylinder 7 . Hydraulic cylinders 6 and 7 are hinged on stand 10 mounted on supporting frame 2. The drive is actuated by power plant 8 , for example, a hydraulic motor [20].

Working body 3 of the frontal fire fighting soil-thrower is made in the form of knives-throwers 11 placed on milling disc 12 mounted on shaft 13 . Knives-throwers 11 are made in the form of lituus and mounted on milling disc 12 at angle $\alpha$ between the rear edge of the knife and rotation plane of milling disc 12 and rotated relative to the trailing edge in the direction of motion at angle $\beta$. The installation of knives 11 at $\alpha$ and $\beta$ angles reduces the effort to separate the soil chips from the array and eliminates the possibility of friction of the rear surface of the working body on the cut surface of the array cut.

Frontal fire fighting soil-thrower works as follows. The tractor blade removes the upper part of the soil layer, which may contain materials that support the combustion process, as well as foreign bodies in the form of stones, etc. At the same time, the frontal fire fighting soil-thrower is sunk into the cultivated soil to certain depth $h$ by force of its own weight, and, if necessary, it is reloaded with the help of hydraulic cylinder 7. Power plant 8 , for example, the hydraulic motor operating from the hydraulic system of the base machine, transmits torque to the shaft of working body 3 of the frontal fire fighting soil-thrower. From shaft 13, the torque is transmitted to working body 3 , which rotates and moves forward to separate the soil chips from the massif, and also cuts and evenly distributes the cut-off soil volume across the width of the mineralized strip. Uniform distribution of soil across the width of the mineralized strip is carried out by

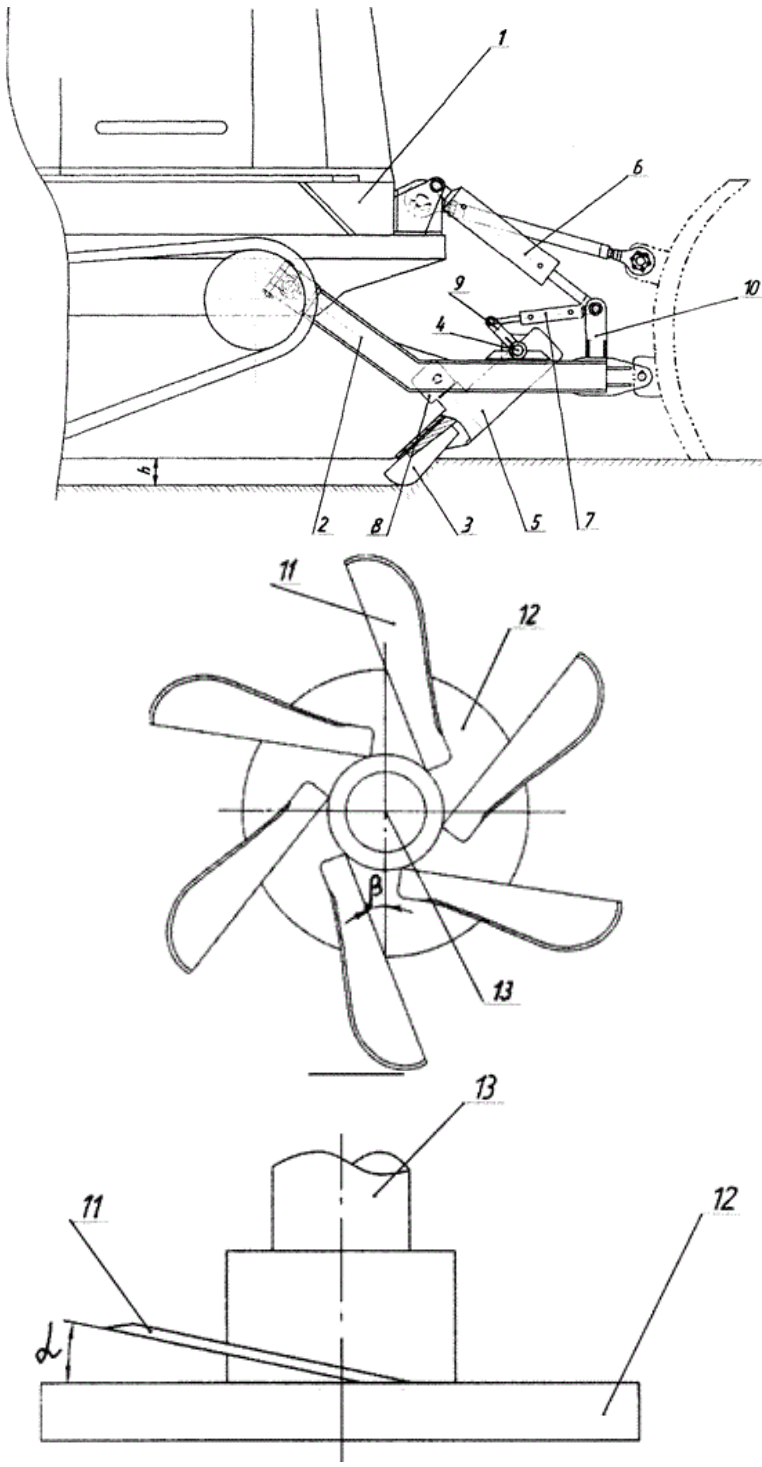

Fig. 2. General view of frontal soil-thrower

knives-throwers 11, made in the form of lituus.

The thickness of the soil chips is greater than the path traveled by the tractor during the cutting cycle, which is ensured by angle $\alpha$. Throwing occurs as a result of giving kinetic energy from knives-throwers 11 to the cut-off part of the ground. Guide casing 5 is used to guide the throwing ground. When meeting an obstacle, the working body is lifted above it, as it is mounted pivotally on swing axis 4 .

Reduction of energy intensity is carried out by reducing efforts to separate soil chips from the array and eliminate the occurrence of friction on the back surface of the working body on the cut surface of the array, installing knives-throwers on the milling disk at $\alpha$ and $\beta$ angles.

The fire fighting milling soil-thrower relates to devices designed to extinguish ground fires by throwing dirt, as well as for laying fire-fighting mineralized strips in dry massifs. Fig. 3 shows a general view of the milling fire fighting soilthrower [21]. 


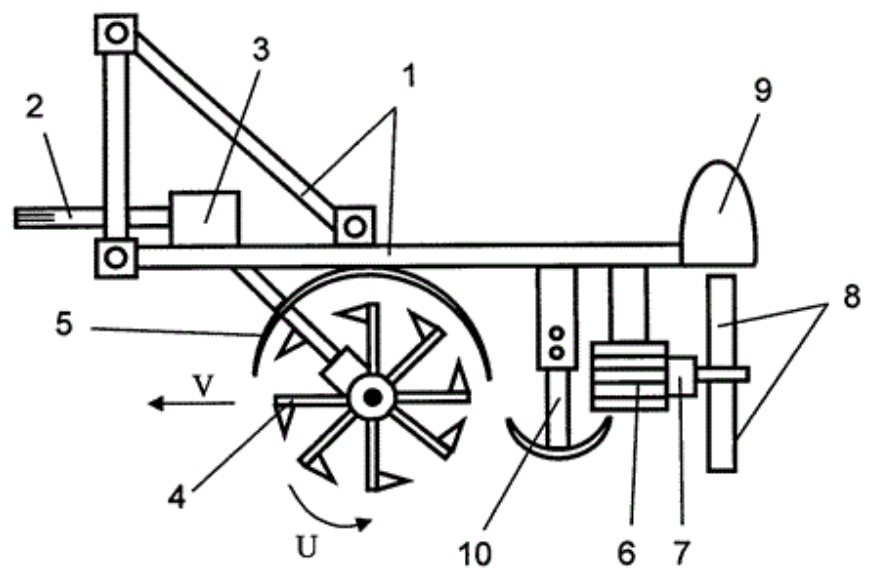

Fig. 3. General view of fire fighting milling soil-thrower

The firefighting milling soil-thrower consists of a frame with hinged device 1 , driveshaft 2 , gearbox 3 , milling drum with L-shaped knives 4, protective casing 5, two hydraulic motors 6 with safety devices 7 , two milling throwers 8 , two guiding covers 9 and skid 10, which is height adjustable.

The fire fighting milling soil-thrower works as follows. When turning on the tractor's power take-off shaft, the torque is transmitted from the engine to driveshaft 2 via gearbox 3 to the transmission of cutter drum 4 , which begins to rotate. Cutter drum 4 is a shaft with spherical disks loosely mounted on it, to which L-shaped knives are attached around the circumference. Rubber sleeves are installed between the discs with L-shaped knives to prevent the knives from breaking when they encounter hard soil inclusions (stones, roots, stumps, etc.). During the forward movement of the unit, cutter drum 4 , covered with protective casing 5 , rotates and the Lshaped knives mill the ground, forming a loosened strip of soil. Next there are two cutters-throwers 8 , located on frame 1 transversely; each rotates from its hydraulic motor 6 through safety device (clutch) 7. Hydraulic motors 6 are driven from the tractor's hydraulic system. Rotating, cutters-throwers 8 capture the loosened soil and throw it on two guiding housings 9 located above cutters-throwers 8 at a certain angle. Next, the soil bounces off housing 9 and scatters on both sides of the soil-thrower. The distance at which the soil is discarded is adjusted by guide housings 9 by raising or lowering them by means of hydraulic cylinders. When moving, the fire fighting milling soil-thrower rests on skid 10 , which slides over the soil surface. To change the milling depth of cutter drum 4, the stand of supporting skid 10 is made to be telescopic one. Height adjustment is carried out using bolts and vertically located holes on the skid stand.

Due to the presence of a rotating cutter drum with Lshaped knives in the soil-thrower design, which preliminarily grind dense and heavily turf-covered soil, milling and throwing machines are facilitated, the amount of soil fed into the fire zone increases, the uniformity of soil distribution and its range increases. The effectiveness of the fight against fire also increases due to the increase in the forward speed of the unit and its cross-country ability in conditions of soils saturated with roots and forest debris, as well as overgrown with low tree-shrub vegetation.
When laying fire-fighting mineralized strips, only cutter operates (the hydraulic motors are switched off), and the firefighting milling soil-thrower is used as a fire-break maker.

When extinguishing the edges of ground fires, the cutter drum and cutter-throwers simultaneously rotate, which knock down the flame with a flow of flying soil.

The design of the proposed fire fighting milling soilthrower helps to improve the efficiency of soil-thrower under conditions of compacted, cohesive, turf-covered soils, covered with small trees and shrubs, saturated with roots or a small amount of forest debris. At the same time, the soil-thrower can be used to prevent and extinguish ground fires, as well as for strip soil preparation for forest crops on clearings, burns, turfcovered, dense soils covered with low shrubs.

The soil-thrower and fire-break maker is designed to extinguish ground fires with soil, as well as for laying protective mineralized strips, especially in waterless arrays, and solves the problem of creating a soil-thrower with high efficiency of working in soil conditions saturated with trees and shrubs and compacted cohesive soils, as well as performing the function of a fire-break maker.

The soil-thrower and fire-break maker (Fig. 4) consists of frame 1 , mounted device 2, two spherical disks 3 , cuttermilling machine 4 , cardan drive 5 , transmission with safety device 6, guide casing 7, gearbox-reverse 8. Plow-shell shells may be set instead spherical discs, one of which is left turning, and the second - right turning [22].

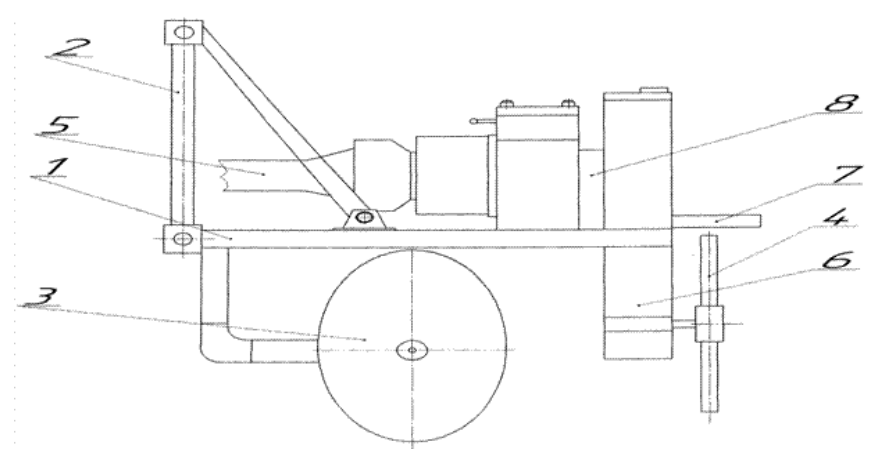

Fig. 4. General view of soil-thrower and fire-break maker

The soil-thrower and fire-break maker works as follows. When the tractor's PTO shaft is turned on, the torque is transmitted from the engine to cardan drive 5 and gearboxreverse 8 to transmission 6 , to cutter-thrower 4 . Directed to the forward movement of the unit, spherical disks or rotary dump bodies are buried in the soil, cut the layers and shift them to the center, forming a soil-ground shaft in a loosened state. Thereby they facilitate the process of cutting the soil by the cutter-thrower, reduce the energy consumption for milling and increase the volume of the mass of supplied soil to the fire zone. Next, a cutter-thrower grabs the soil from the shaft and partly below the shaft and throws it into the fire zone.

For laying fire-fighting mineralized strips discs or plow-up housings are rearranged to work according to the "throw-out plowing" scheme, the cutter-thrower is shut off when laying 
the strips.

Thus, the design of the proposed machine is the soilthrower and fire-break, replacing at least two modern machines and thereby reducing the material intensity of the technological process of fire extinguishing and laying firebreaks; increases the amount of supplied ground for fire extinguishing, increasing the effectiveness of fire fighting, as well as forward speed of the unit and, consequently, its performance.

The 3rd model of "Michigan Sunny Castors" and the tractor soil-thrower and canal digger, developed by the "Dynamics Corporation of America" company, should be noted among foreign soil-throwers.

A common drawback of such designs is the spraying of soil supplied to the area of ignition and its small volume. The soil is actually supplied in the form of a "cloud", which, after settling, does not form a continuous uniform cover on the grass vegetation and forest floor, which would exclude ignition and movement of ground fire.

Another disadvantage is impossibility to use on forest soils saturated with root systems of trees and shrubs. This problem is partially solved by installing additional loosening and safety units.

The most promising design (at the moment) is the soilthrower and the fire-break maker, the construction of which includes a device in the form of a double-sided auger installed in front of the disks. The auger shifts the ground cover from the center to the left and right sides, forming an open mineralized strip. Within this strip, the loosening paw and discs create two shafts in the form of continuous microhills of loose soil. Cutter-throwers provide ground throwing both separately in different directions and in one direction of the fire. Cutter-throwers are placed at a certain distance relative to each other in the longitudinal direction. They rotate on a vertical axis and are installed using an external hydraulic cylinder at an angle to the direction of the unit's movement. The auger is driven by mechanical transmission from the tractor's power take-off shaft. The drive of cutter-throwers is carried out through hydraulic actuators.

Fig. 5 shows a general view of the soil-thrower and the fire-break maker.

The fire soil-thrower and the fire-break maker are comprised of frame 1 , attachment mechanism 2, auger 3 , cultivator 4, spherical disks 5, cutter-throwers - front 6 and back 7 , gearbox housing 8 with axes of cutter-throwers placed in it, connected with hydraulic motors 10 , remote hydraulic cylinder 11 for turning the soil-thrower $s$ in the horizontal plane around vertical axis 19 together with guiding jackets 12 . Auger 3 is driven from the tractor power-take off shaft through cardan drive 16, chain drive 18 and gearbox housing 17. Shank 13 of cultivator tooth 4 is pivotally connected to frame 1 . The cultivator tooth has knife 15 , with the help of which the cultivator tooth can swing behind and up when encountering an obstacle. Under the influence of draw spring 14 after overcoming the obstacle, the cultivator tooth returns to its initial working position $[23,24]$.
The fire soil-thrower and the fire-breaking maker work in the following way: when the hydraulic system and the tractor power-take off shaft are switched on, cutter-throwers 6, 7 are accordingly activated through individual hydraulic motors 10 and auger 3 through cardan drive 16, chain drive 18 and gearbox housing 17. Guiding jackets 12 are installed with the help of guiding plate 9 at angles corresponding to the technical process and soil ejecting distance.

During forward movement of the unit, the rotating auger moves the soil cover to both sides. The cultivator tooth and spherical disks deepen into an open mineralized layer. They loosen the soil and form two microhills in the form of continuous shafts. Next, the cutter-throwers clutch and throw the soil to both

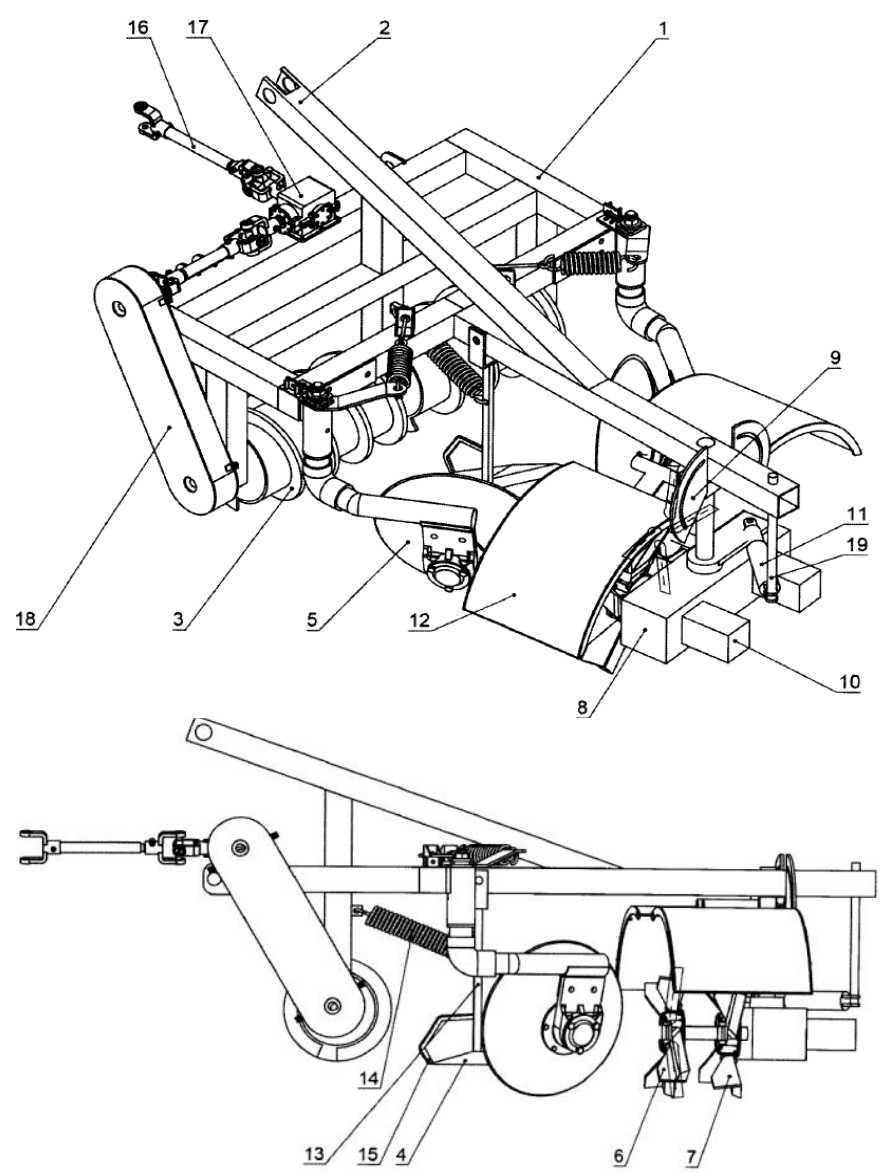

Fig. 5. General view of soil-thrower and fire-break maker

sides to form a mineralized fire break with increased width, or throw the soil to one side (to the left or to the right, depending on the unit position with regard to the fire edge).

For more efficient ground forest fire extinguishing, cutterthrowers with the hydraulic drive, guiding jackets and pivot mechanisms are installed so that the soil would be ejected at an angle from the fire edge. The basic soil mass remains in the fire edge zone, providing complete fire extinguishing. 


\section{CONCLUSION}

Thus, the construction of the proposed machine increases the forward speed of the unit and its productivity. It increases fire-fighting efficiency, covering a significantly longer fire edge with soil in comparison with known soil-throwers. It throws the soil directly in the fire zone, avoiding areas affected by fire. The soil ejecting distance is regulated by the angle of installing guiding casings, as well as by rotor speed of hydraulic motors. Hydraulic motors provide cutter-thrower reversal control.

The use of a fundamentally new technological process, including the formation of a shaft from loosened soil and directionally controlled movement of it, performed by combined working bodies, solves the problem of creating a universal machine that effectively works both in laying firefighting mineralized strips and in extinguishing ground forest fires in conditions of any soil type.

The use of spherical discs mounted on crankshafts ensures formation of a soil shaft for directing it to the fire zone with sufficient amount by cutter-throwers and high permeability in various soil types.

Hinged connection of the guiding housings and their remote control with the help of remote hydraulic cylinders operating from the tractor's hydraulic system allows adjusting the range and amount of soil thrown over a wide range, reducing the amount of soil from the opposite side of the fire edge and increasing it towards the fire.

The possibility of aggregating a new forest fire machine with widespread wheeled or tracked tractors of the 2 nd and 3rd classes solves the problem of its widespread use in forestry.

\section{Acknowledgment}

The reported study was funded by the Council for Grants of the President of the Russian Federation according to research project № MK-6621.2018.8.

\section{References}

[1] Afzaal Hamra, and Zafar Nazir Ahmad "Robot-based Forest Fire Detection and Extinguishing Model", 2nd International Conference on Robotics and Artificial Intelligence (ICRAI). Natl Univ Sci \& Technol Coll E\&ME Pakistan, Islamabad, Pakistan, November 01-02 2016, pp. 112-117.

[2] J. Li, X. Li, C. Chen, H. Zheng, and N. Liu "Three-Dimensional Dynamic Simulation System for Forest Surface Fire Spreading Prediction", International Journal of Pattern Recognition and Artificial Intelligence, vol. 32, issue 8,1 August 2018, DOI: 10.1142/S021800141850026X

[3] T. Artès, A. Cardil, A. Cortés, T. Margalef, D. Molina, L. Pelegrín, and J. Ramírez "Forest fire propagation prediction based on overlapping DDDAS forecasts", Procedia Computer Science, vol. 51, issue 1, 2015, pp. 1623-1632. DOI: 10.1016/j.procs.2015.05.294

[4] P. Wu, F. Chu, A. Che, and M. Zhou "Bi-Objective Scheduling of Fire Engines for Fighting Forest Fires: New Optimization Approaches", IEEE Transactions on Intelligent Transportation Systems, vol. 19, issue 4, April 2018, pp. 1140-1151. DOI: 10.1109/TITS.2017.2717188
[5] D.P. Kasymov, V.N. Fateyev, and V.P. Zima "Methods and devices used in the wildfire localization for the protection of forest ecosystems", Proceedings of SPIE - The International Society for Optical Engineering, vol. 10466, 2017, DOI: 10.1117/12.2287438

[6] D.G. Green "Shapes of simulated fires in discrete fuels", Ecological Modelling, vol. 20, issue 1, October 1983, pp. 21-32. DOI: 10.1016/0304-3800(83)90029-7

[7] G.D. Richards "Numerical simulation of forest fires", International Journal for Numerical Methods in Engineering, vol. 25, issue 2, June 1988, pp. 625-633. DOI: 10.1002/nme.1620250222

[8] D.G. Green, A.M. Gill, and I.R. Noble "Fire shapes and the adequacy of fire-spread models", Ecological Modelling, vol. 20, issue 1, October 1983, pp. 33-45. DOI: 10.1016/0304-3800(83)90030-3

[9] I.R. Noble, A.M. Gill, and G.A.V. Bary "McArthur's fire-danger meters expressed as equations", Australian Journal of Ecology, vol. 5, issue 2, June 1980, pp. 201-203. DOI: 10.1111/j.1442-9993.1980.tb01243.x

[10] W. Liu, S. Wang, Y. Zhou, L. Wang, J. Zhu, and F. Wang "Lightningcaused forest fire risk rating assessment based on case-based reasoning: a case study in DaXingAn Mountains of China", Natural Hazards, vol. 81, issue 1, 1 March 2016, pp. 347-363. DOI: 10.1007/s11069-0152083-1

[11] M. Mikulas "Forest fires extinguishing using suitable fire-fighting equipment", Advanced Materials Research, vol. 1001, 2014, pp. 318323. DOI: 10.4028/www.scientific.net/AMR.1001.318

[12] I.M. Bartenev, S.V. Malyukov and S.S. Kirillova, "The Efficiency of the application of a soil-thrower under high fire hazards", Journal of Forestry Engineering, vol. 5, no. 3 (19), 2015, pp. 200-209.

[13] P.E. Goncharov, P.I. Popikov, S.V. Malyukov, M.A. Gnusov, A.V. Butin, K.P. Andreev and I.G. Skobtsov "Results of experimental studies of the operation of a combined machine for extinguishing forest fires", Polytematic network electronic scientific journal of the Kuban State Agrarian University, no. 84, 2012, pp. 406-415.

[14] M.V. Drapalyuk, S.V. Malyukov and M.A. Gnusov, "Improving the process of soil-thrower" Young Scientist, no. 1 (03), 2014, pp. 22-24.

[15] I.M. Bartenev, M.V. Drapalyuk, P.E. Goncharov, M.A. Gnusov, A.A. Tambi and V.E. Klubnichkin "Combined forest fire soil-thrower and recommendations for its use" Polytematic network electronic scientific journal of the Kuban State Agrarian University, no. 84, 2012, pp. 174184.

[16] M. N. Lysych, M. L. Shabanov and A. V. Chernyshev "Soil-thrower for extinguishing forest fires", Actual areas of research of the XXI century: theory and practice, no. 5, issue 1 (16-1), 2015, pp. 241-245.

[17] D.V. Eskov "Optimization of parameters and a mathematical model of the process of soil throwing using a combined milling soil-thrower", Actual areas of research of the XXI century: theory and practice, vol. 2, no. 4-2 (9-2), 2014, pp. 208-212.

[18] D.V. Eskov, V.V. Tsyplakov, S.V. Fokin and D.V. Tsybaev "Perspective directions for the improvement of the working bodies of soil-thrower", Actual areas of research of the XXI century: theory and practice, no. 2-2 (7-2), 2014, pp. 214-219.

[19] M.E. Konyushenkov "Universal fire fighting soil-thrower", Patent RF no. 2628725 .

[20] E.I. Maksimov, I.S. Fedorchenko, I.V. Golubev and D.A. Golubev "Frontal fire fighting soil-thrower", Patent RF no. 2400274.

[21] D.V. Eskov, V.V. Tsyplakov, S.V. Fokin and D.V. Tsybaev "Fire fighting milling soil-thrower", Patent RF no. 144715.

[22] I.M. Bartenev, M.V. Drapalyuk and M.A. Gnusov "Fire fighting soilthrower and fire-break maker", Patent RF no. 2496540.

[23] I.M. Bartenev, Z.K. Emtyl, M.V. Drapalyuk, L.D. Bukhtoyarov and P.I. Popikov "Fire fighting soil-thrower and fire-break maker", Patent RF no. 2541987.

[24] I.M. Bartenev, S.V. Malyukov, M.A. Gnusov, and D.S. Stupnikov "Study of efficiency of soil-thrower and fire-break majer on the basis of mathematic simulation", International Journal of Mechanical Engineering and Technology, vol. 9, issue 4, 2018, pp. 1008-1018. 